\title{
Prior publication on the web: new journal policy
}

Authors, journal editors, and publishers are needy people. Some of their needs are mutual: authors want editors to publish their papers, and editors want authors to crush forward to be published in their journals. Other needs are potentially at odds. Authors want their work to be known as far and wide as possible, while editors want their journals to be the exclusive vehicle that displays the work. This promotes prestige for the journal as a groundbreaking forum and makes publishers happy as they milk the cash cow that comes with a high impact and well read journal.

Journals have always been very protective of their rights in seeking to publish original material. Nearly all journals require authors to sign copyright agreements. Duplicate or substantially identical publication in other journals is considered one of the most heinous sins of authorship, and many journals stress to authors that giving widespread publicity to papers in the media before publication can hit the publication kill button. The reasoning behind these rules partly concerns the commercial survival for journals. Editors and publishers believe that many of their readers will not be prepared to pay good money to read reports that have been published under other titles in other journals or which they have already heard discussed at length in the media.

Many journals, however, also recognise that researchers present papers based on their intended presentations at conferences. Journalists attend conferences and report important and newsworthy papers. Authors often circulate "not for citation" drafts or preprints of their papers to colleagues, seeking ways of improving their quality. Together, these activities can create sometimes widespread awareness of papers before they are published in peer reviewed journals.

These distribution methods are nothing compared to the potential of the world wide web for allowing readers access to reports. The exponential growth of web access and the ability of even those with basic web skills to build and promote their own web site has seen a huge growth in the dissemination of papers. These can range from draft working papers to officially ratified documents from large international organisations. The editor of the Lancet believes it is impossible for scholarly journals to police prepublication on the web. ${ }^{1}$

Recently, Tobacco Control has received several submissions that are already "out there" on the web. Our initial inclination was to reject these papers without review, as is the policy with journals like $\mathcal{F} A M A$ and the New England Fournal of Medicine. Our parent publication, the BMF, has decided otherwise and announced that it would consider papers for publication that were already published in cyberspace. ${ }^{2}$ Editor Richard Smith concluded: "Communication in science and medicine will not be well served by standing in the way of publication in many versions, and the $B M \mathcal{F}$ is willing to consider for publication eprints that have been posted on web sites so long as their status as eprints is clear. In the meantime, authors, editors, and publishers have more work to do to make the status of articles entirely clear."

We canvassed the views of our editorial board and received passionate support for both opening or closing the journal to papers previously published on the web. One member best articulated the concerns of those opposed to an open door policy by writing "this is good for science, but bad for journals . . . why bother to read it in the journal after it's been on the web (It has been documented that physicists read their preprint web sites, but not their journals) ... I would hate for $T C$ to be filled with papers that people have already read."

Those in favour of being open to previously published papers mainly argued from two perspectives. First, prior web publication could be seen as simply a more efficient way of having a wider audience "review" a paper, although there is little information on the extent to which this actually occurs. Further, publication in a peer reviewed journal would always be considered "hard" publication while self publication on the web would inspire less confidence about quality.

We have decided that for at least 12 months, $T C$ will be willing to consider papers that have been previously published on the web. Authors must acknowledge this on submission and if the paper is eventually accepted by $T C$, we will require authors to take down the original version from their site and replace it with the version that has been peer reviewed for $T C$, noting that it has been published in our journal. We will also require that authors of submitted papers note on the www sites where the eprint is published that the paper or a version of it has been submitted to $T C$ for peer review.

As a quarterly, we are currently able to publish around 45 papers a year. This year we are on track to receive 120 candidate papers. Importance, quality, and originality are the three main criteria the senior editors consider when deciding whether to put a paper into peer review. A paper that has been published on the web has tarnished originality compared to a paper that is truly new to the world. Prior publication on the web will therefore be considered as a relevant factor in assigning priority to papers for a position in our limited space. Authors will need to weigh up whether publishing on the web before submission is worth the risk. Truly important, quality papers will be unlikely to have their fate changed by prior web publication. But those on the margin may well be tipped into rejection.

We will review this policy every year against concerns that we might become too much of a "recycling shop" and against readers' reactions. The Medical fournal of Australia has trialed a system where submitted papers are placed on its web site for peer review. ${ }^{3}$ We may well decide to encourage authors to "prepublish" their papers on our web site, rather than on their own. Again, this will require debate. For example, we would not wish to send any signal to authors that by prepublishing with us, they were queue jumping toward "hard" publication. Constant change is here to stay!

Editor

SIMON CHAPMAN

\footnotetext{
1 McConnell J, Horton R. Having electronic preprints is logical. BMf 1998; 316:1907.

2 Smith R. What is publication? BMf 1999;318:142.

3 Bingham CM, Higgins G, Coleman R, et al. The Medical Journal of Australia Internet peer-review study. Lancet 1998;352:441-5.
} 